\title{
Hippocampal sparing in brain radiotherapy
}

\author{
Monika Konopka-Filippow ${ }^{1,2}$, Ewa Sierko ${ }^{1,2,3}$, Marek Z. Wojtukiewicz ${ }^{1,3}$
}

Radiotherapy is one of the principal methods for treating brain cancer. Over recent years, a decline in patient quality of life has increasingly been observed in those undergoing brain irradiation, where hippocampal-dependent cognitive function has become impaired.

The hippocampus is a paired structure of the limbic system situated in the medial temporal lobes of the telencephalon. Preliminary findings suggest that irradiation damaged neural stem cells in the hippocampus undergo apoptosis, resulting in deteriorating cognitive function.

Despite the technical aspects for affording hippocampal avoidance during irradiation, much controversy still surrounds the techniques that shield the hippocampus without reducing the benefits of the intended radiotherapy for a given clinical condition. Furthermore, a tolerated radiation dose sufficient for preserving neural stem cell function has not been yet established.

Delivering a method for an unequivocal assessment of cognitive function, post-irradiation, is also fraught with difficulty. Hitherto, only subjective psychological testing have been applied such as MMSE, HVLT or AVLT methods. Objective methods for optimally determining radiation-induced injury to the hippocampal region are still being investigated.

NOWOTWORY J Oncol 2016; 66, 4: 299-306

Key words: hippocampal sparing, brain radiotherapy, cognitive function

\section{Introduction}

Brain tumours constitute a considerable clinical problem because they affect this vital organ of the human body and where choosing an effective and safe treatment poses many challenges. During recent decades, morbidity rates for primary brain tumours in Poland have increased with around 3000 cases now reported annually. This represents $2 \%$ of all cancers for both genders and the average age at diagnosis is between 50 and 60 years. Brain metastases (BMs) are twice more likely to occur than primary brain tumours, at rates of around $15 \%-20 \%$ in all those adult patients with cancers of varying origin. In children however, cases of BM account for only $0.5 \%$ of all brain cancer [1].

One of the basic methods for treating patients suffering brain cancer, both primary and secondary, is by radiotherapy (RT). The advantages of using RT over other therapeutic methods are, amongst others, the possibility of eliminating not only the macroscopically visible tumour, but also the micro-foci (eg. in cases of prophylactic cranial irradiation in patients with small cell lung cancer), treating patients with multiple BMs or anticancer treatment of patients diagnosed with inoperable brain tumours. Furthermore, the presence of the blood-brain barrier does not compromise the effectiveness of RT, in contrast to those chemotherapeutic agents which are insufficiently capable of crossing this barrier. In planning brain RT, due consideration must be taken of many critical structures, termed 'Organs at Risk' (OAR) which are especially sensitive/susceptible to ionizing radiation. These include, amongst others, lenses, optic nerves and crossover junction between the optic nerves and brain stem. Advanced RT techniques enable a more improved confocal beam radiotherapy directed towards the RT target area, whilst sparing critical structures which play special roles whenever tumours are located within the brain.

\footnotetext{
${ }^{1}$ Department of Oncology, Medical University in Białystok, Poland 
In patients with primary brain tumours, $\mathrm{RT}$ is applied to a precisely delineated area restricted to the tumour or the tumour bed (+/-swelling of the tissues around the tumour, +/- margin of tissue surrounding the tumour). Quite often clinical circumstances dictate irradiating an extensive area of the brain (eg. in cases of infiltrating high malignant grade gliomas) which may lead a deteriorating quality of life for patients after treatment. It should however be stressed that using combination therapy in patients with brain tumours increases the chances of an ever longer survival. An example is afforded by patients suffering from glioblastoma multiforme (glioblastoma), where the combination of surgical treatment with adjuvant chemoradiotherapy improves local control (LC) and extends overall survival (OS) [2]. At the same time, patients undergoing antineoplastic therapy are more likely to suffer from worsening psychomotor dysfunction.

A slightly different situation exists for patients with metastases diagnosed as having just single BMs, in the absence of extracranial metastatic disease. In such cases, the risk of the brain treatment failing is relatively small which for most clinical situations, with suitably small volume metastases, makes possible the irradiation of the tumour metastasis by using stereotactic techniques of radiotherapy/radiosurgery (SRT/SRS) instead of undergoing whole brain RT (i.e. WBRT). By such means, the adverse effects of RT are lessened [3]. In cancer patients with current BM and extracranial metastases, the potential benefits from adding WBRT to SRT nevertheless outweigh their adverse effects [4].

Through using WBRT on BM patients the risk of disease progression in the brain becomes reduced, thereby improving patient Quality of Life (QoL) and in some cases extending their OS [5-8]. Despite this, there is a loss of neurocognitive function post-WBRT that is manifest and intensified, the longer the survival time of patients becomes $[9,10]$. A number of prospective randomised clinical trials have demonstrated that WBRT improves LC patients with BM [5-7] but that its adoption is associated with declining QoL in terms of cognitive function when compared to the pre-treatment status [11].

The term 'cognitive function' refers to those mental processes responsible for information processing which inputs from the external environment and is internalised in the mind, that enables knowledge acquisition through interpreting reality and is essential for normal mental function. The basic cognitive functions are perception, attention and memory, whilst complex ones include thinking and imagination [12].

Deficits in cognitive function post-RT of the brain are apparent primarily as a short-term memory loss manifested as verbal memory dysfunction, problems with learning and being able to utilise newly acquired information $[13,14]$. The process of memorising is closely linked to the functioning of granule cells from the hippocampal dentate gyrus [15].

\section{The hippocampus as an organ at risk}

The hippocampus is a twinned component of the limbic system located in the telencephalon within the temporal lobes of the cerebral cortex neighbouring the lateral ventricles (Fig.1). It plays a key role, inter alia, in learning, remembering, creating memories and relaying information from short-term to long-term memory together with the ability of remembering information [16]. The so-called neural stem cells (NSCs) are responsible for such functions and are located in the granular zone of the dentate gyrus within the hippocampus, which are the only brain cells possessing mitotic potential [17]. These cells in adult mammal brains are concentrated around only two niches: the subventricular zone (SVZ) of the anterolateral recess and the subgranular zone (SGZ) of the dentate gyrus within the hippocampus (Fig.1).

Maintaining cellular homeostasis in the hippocampus enables NSCs to undergo: proliferation, differentiation, normal cell function and apoptosis [18]. A year after birth, the numbers of NSCs in the human brain rapidly fall, after which, in subsequent years of childhood and adulthood they decrease at a more measured pace [19-21]. These cells proliferate in the subgranular zone, and then migrate circumferentially, becoming integrated with mature granular cells of the dentate gyrus within the hippocampus, and then mature into fully functional nerve cells [22]. In the human adult, NSC proliferation assures the formation of around 700 new nerve cells daily and that $1.75 \%$ of all neurones are replaced by new ones [23]. There are reports of NSCs migrating from the hippocampus to more remote area of the brain to replace damaged astrocytes or oligodendrocytes by transforming themselves into the given cell type [24, 25] (Fig.2).

NSCs are sensitive to various injuring factors, such as ischemia, stress or ionizing radiation [26]. Indeed, studies performed on mice have shown that ionizing radiation induces breakage of double-stranded DNA in NSC precursor cells leading to apoptosis [26]. This RT-dependent loss of NSCs leads to a deficient cognitive function, especially disorders of learning and memory [27-29]. In studies on young rats and mice subjected to brain RT, most of the enhanced NSC apoptosis in the hippocampus occurred after 12 hours post-RT $[28,30]$, thus indicating radiation-dependent suppression of neurogenesis in precursor NSCs [27, 31, 32].

It is therefore considered that in patients having undergone WBRT, then the observed impairments to learning, memory or spatial processing are the result of damage to the NSCs from the hippocampal dentate gyrus [33]. Interestingly, Mahajan et al. [34] found that damage to the left hippocampus during RT for brain cancer results in impaired learning and delayed recall, however there was no such correlation when tumours from the right side were subjected to RT [35]. The IQ (Intelligent Quotient) was found to decline in patients two years after undergoing conformal SRT (54 


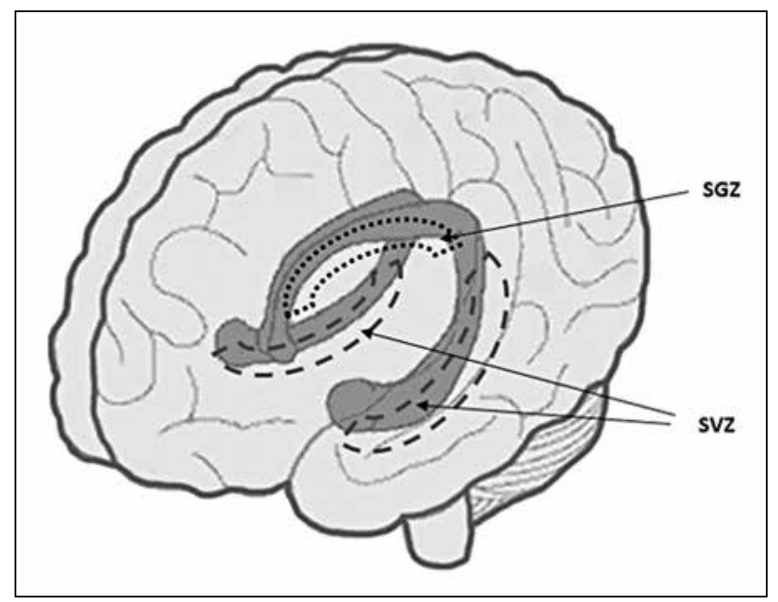

Figure 1. Lower Neural Stem Cells (NSCs) within the hippocampus

Gy in 30 fractions), whenever a radiation dose exceeded $42.5 \mathrm{~Gy}$ and was given to more than $13 \%$ by volume of the left temporal lobe, when compared to the pre-treatment status [35].

A study by Monje et al. [36] demonstrated that NSCs neurogenesis becomes inhibited by inflammation in the hippocampus through damage to the actinic granular zone of the dentate gyrus. Subsequent studies by this group conducted on rats revealed that the levels of dose fractionation and neurogenesis were correlated; i.e. a single fractional dose of 10 Gy induced a $62 \%$ decrease in the NSC proliferation rate whilst reducing the severity of neurogenesis by $97 \%$ within the hippocampal area when compared to the effects achieved by a single dose of 5 Gy which, according to this study, was found to be the damage limiting dose for NSCs [36, 37].

From the radiobiological viewpoint, the effect of ionizing radiation on the hippocampus is not completely understood and remains still debateable. According to the QUANTEC study (Quantitative Analysis of Normal Tissue Effects in the Clinic), the brain a / $\beta$ ratio/index is 2.9 [39] but this is not explicitly specified for the hippocampus. Some investigators take an $\alpha / \beta$ ratio of between 2 and 3 for the hippocampus [40], whilst others use a value of 10 for hippocampal NSCs; the same as for stem cells [41, 42]. It is worth emphasising that preclinical experiments have demonstrated that doses of even 2 Gy cause apoptosis in NSCs $[27,43]$, thereby reducing the survival of these cells by even $50 \%$ [44].

Because of the key role that NSCs play (from the hippocampal dentate gyrus) in neurogenesis [45-48], any brain irradiation caused losses result in impaired cognitive function, especially that of memory $[27,49-53]$. In a 18-month follow-up study on patients with benign or low-grade glioma subjected to SRT, Gondi et al. [44] showed that the higher dose of 7.3 Gy (normalised to an equivalent dose of 2

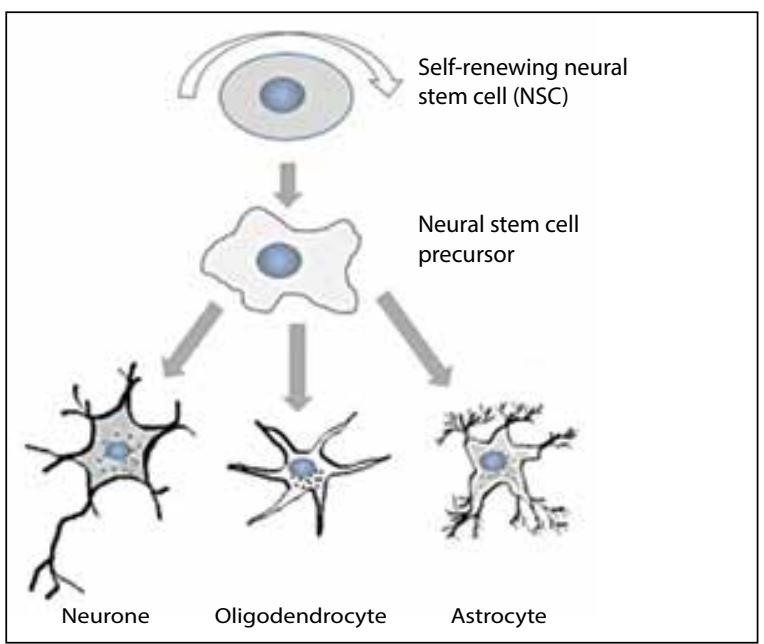

Figure 2. Neurogenesis of Neural Stem Cells

Gy) applied to at least $40 \%$, by volume, of the hippocampus causes damage to the NSCs - resulting in problems with memory and learning.

\section{Onset time of cognitive dysfunction, after brain RT}

Those patients fortunate to experience long-term survival (i.e. over 12 months) were found to suffer from late side effects after brain RT, especially from the hypofractionated type, which were manifested mainly by dementia and psychomotor slowing [54]. Only after 2000, did cognitive function begin to be carefully evaluated following brain RT through using specialized psychological testing.

A RTOG 0914 study on 445 BM patients undergoing WBRT demonstrated that both RT hypofractionation (30Gy/ /10fr) as well as conventional RT (40Gy/20fr) lead to a significant reduction in cognitive function. Using the'Mini Mental Stage Examination' (MMSE) a clear decline in cognitive function was observed in both groups after the 2 nd and 3rd month post-RT [55].

In a multicenter phase III study on 401 BM patients undergoing WBRT (30Gy/10fr), a significant decline in cognitive function was demonstrated based on a test of verbal fluency 'Controlled Oral Word Association' (COWA) in the 4th month after RT, which then improved after 15 months post-RT [56]. In the Phase II RTOG 0933 study, a verbal learning material test was used, i.e. the 'Hopkins Verbal Learning Test'(HVLT), which showed that when the hippocampus is spared in BM patients during WBRT, then there is a less severe early loss of cognitive function already within the first 4 months after the RT, when compared to the pre-treatment status [57-59].

Similarly, Chang et al. [57] also observed a smaller loss in cognitive function, assessed by HVLT, in learning and short term memory in patients with 1-3 BM treated with only brain SRT (which facilitated giving a lower radiation dose to 
the hippocampus) as compared to those receiving WBRT. A study by Welzel et al. [59] used the AVLT test (Auditory Verbal Learning test) which reported lowered verbal memory already 6-8 weeks after completing WBRT in BM patients. In a phase III RTOG 0214 clinical study on patients with small cell lung cancer (at stage III clinical severity) undergoing prophylactic cranial irradiation (PCl), a clear reduction of cognitive function was observed at 3 months after brain RT when assessed by the MMSE test [60].

Cognitive disorders are also described in post-RT patients suffering nasopharyngeal carcinoma where, at approximately 5.5 years after radical $\mathrm{RT}$, they exhibited memory and learning dysfunction compared to people of similar age but untreated with RT [61]. However, another prospective study on patients with nasopharyngeal carcinoma treated with RT by using Intensity Modulated Radiation Therapy (IMRT) found that, after 18 months post-RT, the test results of cognitive function in patients receiving an average dose exceeding $36 \mathrm{~Gy}$ to the temporal lobe were significantly different to those results prior the RT [62].

In summary, applying RT to the area around the brain affects cognitive function, which can already become apparent onwards from the second month after RT treatment, peaking at about 4 months post-RT [63] (Tab. I).

\section{Cognitive impairment/dysfunction following brain RT}

Around $90 \%$ of BM patients evince some loss of cognitive function even before starting RT whilst in two thirds cases there are further losses in cognitive function following brain RT [64]. This deficit/deficiency is caused not only by the presence of brain cancer itself, but also through the progressive effects of extracranial chemotherapy $(\mathrm{CHT})$ or adjuvant therapy (including the use of opioids, steroids) as well as the presence of comorbidities or the natural deterioration of cognitive functions in elderly patients $[65,66]$.

A key factor for maintaining normal mental function in patients with brain tumour lesions is to prevent their progressing in the brain through, for example, the use of WBRT [65]. The search for alternatives to preserve or improve cognitive function, (for instance by pharmacological means), have not achieved the desired results; an example is afforded by the RTOG 0614 study that used memantine as a potential neuro-protecting agent during WBRT and which showed no effect on cognitive maintenance [67].

The most commonly reported deficits in cognitive function after brain RT is memory impairment; often short-term, sporadic-deferred [56, 57, 60,68-70]. Ones less common are in remembering/recalling information and in learning $[57,68-70]$. Those also reported include impaired verbal memory, necessary for understanding a read text $[56,59]$. In addition, impaired fine motor function can be observed in the upper limbs and as well as in executive function; the higher cognitive processes determining responses to new and difficult/challenging situations, such as initiating and halting a given response, planning or organising [56]. It should be stressed that the deterioration, to any extent, of each cognitive function after WBRT leads to a reduced QoL $[85,89]$.

\section{The incidence of neoplastic lesions in the hippocampus region}

As yet, it is unclear whether the therapeutic gain from sparing the hippocampus outweighs the risk of disease progression at this location. A study by Gondi et al. [71] on 371 out of 1133 BM patients diagnosed by post contrast MRIT1, observed that tumours located in the hippocampus region (i.e. the hippocampus including a surrounding $5 \mathrm{~mm}$ margin) account for only up to $3 \%$ BM cases and occur in around $8.6 \%$ of patients with brain cancer progression, for which there were no metastases present within the hippocampus itself. Marsh et al. [72] demonstrated that the majority of metastases in the limbic system area occurs in patients with multiple BM (> 3). It is worth emphasising that the SVZ, in which the NSCs are located represents $2.23 \%$ of the whole brain volume [73]. It turns out that the risk of metastasis in the hippocampal area is approximately $0.5 \%$ for oligometastatic disease, i.e. up to $3 \mathrm{BM}$ and approximately $1.5 \%$ in cases of multiple BM [73].

Metastasis in the SVZ more often occurs in patients with small cell lung carcinoma (at $2.7 \%$ ) compared to patients with other cancers $(0.84 \%)$, such as non-small cell lung cancer (0.82\%) and breast cancer (1.3\%) [73]. Preliminary results from most studies indicate that the therapeutic gain achieved when implementing hippocampal sparing procedures during brain RT, (i.e. contouring hippocampal TK images and with fusing/integrating CT images from MRI in planning RT with a small $5 \mathrm{~mm}$ margin), outweighs the potential risk of local failure $[80,86]$. However, in the possible event of metastases appearing within the hippocampal area then SRT may be considered [71].

\section{Technical means for providing hippocampal sparing during brain RT}

Sparing the hippocampal region of the brain during RT poses a technical challenge in that highly specialised radiotherapy techniques need to be applied such as IMRT, which provides protective covering/shielding for one or both of the centrally located hippocampi according to the patient's clinical requirements (Table II).

\section{Hippocampal sparing in patients with primary brain tumours}

There is scant research on this issue. Marsch et al. [92, 93] have shown that for patients undergoing IMRT in the surroundings of the brain tumour, it is possible to reduce their 
Table I. Impairment of cognitive function in patients after brain radiotherapy

\begin{tabular}{|c|c|c|c|c|}
\hline Study, year & RT schedule & $\begin{array}{l}\text { Number } \\
\text { of patients }\end{array}$ & $\begin{array}{l}\text { Observation } \\
\text { time (months) }\end{array}$ & Cognitive function test and significant cognitive decline. \\
\hline Sun et al., 2011 [60] & $\mathrm{PCl} 30 \mathrm{~Gy} / 15 \mathrm{fr}$ & 163 & $3,6,12$ & $\begin{array}{l}\text { HVLT, MMSE - Significant decrease }(p<0.0001) \text { in immediate HVLT } \\
\text { response after } 3 \text { and } 6 \text { months and deferred response decreased } \\
\text { after } 6 \text { months }\end{array}$ \\
\hline \multirow[t]{3}{*}{ Wolfson et al., 2011 [90] } & $\mathrm{PCl} 25 \mathrm{~Gy} / 10 \mathrm{fr}$ & 131 & 6,12 & HVLT, COWA - declining HVLT outcomes by $62 \%$ after 12 months \\
\hline & $\mathrm{PCl} 36 / 18 \mathrm{fr}$ & 67 & & HVLT, COWA - declining HVLT outcomes by $85 \%$ after 12 months \\
\hline & $\begin{array}{l}\mathrm{PCl} 36 / \\
2 x d a i l y / 24 \mathrm{fr}\end{array}$ & 66 & & HVLT, COWA - declining HVLT outcomes by $89 \%$ after 12 months \\
\hline Chang et al., 2009 [7] & $\begin{array}{l}\text { WBRT + SRS } \\
30 \mathrm{~Gy} / 12 \mathrm{fr}\end{array}$ & 28 & 3.5 & HVLT — declining deferred memory after 3 months \\
\hline \multirow[t]{2}{*}{ Welzel et al., 2008 [10] } & WBRT 40Gy/20fr & 16 & 1.2 & AVLT — declining outcomes by $57 \%$ after 2 months. \\
\hline & $\mathrm{PCl} 36 \mathrm{~Gy} / 18 \mathrm{fr}$ & 13 & & AVLT — declining outcomes by $44 \%$ after 2 months. \\
\hline Meyers et al., 2004 [14] & WBRT 30Gy/10fr & 208 & 12 & HVLT, COWA - decreasing cognitive function in both by $48 \%$ \\
\hline
\end{tabular}

Table II. Selected studies where hippocampal sparing was adopted

\begin{tabular}{|c|c|c|c|c|c|c|}
\hline \multirow[t]{2}{*}{ Study, year } & \multicolumn{6}{|c|}{ Hippocampal dose } \\
\hline & $\begin{array}{l}\text { Number of } \\
\text { patients }\end{array}$ & RT & Technique & Fractioning & $D$ max & D av \\
\hline Gutierrez et al., 2007 [82] & 10 & WBRT & HT & $15 \times 2,15 \mathrm{~Gy}$ & - & $5.86 \mathrm{~Gy}$ \\
\hline \multirow[t]{2}{*}{ Gondi et al., 2010 [40] } & \multirow[t]{2}{*}{5} & \multirow[t]{2}{*}{ WBRT } & HT & \multirow[t]{2}{*}{$10 \times 3 \mathrm{~Gy}$} & $12.8 \mathrm{~Gy}$ & *5.5 Gy \\
\hline & & & LINAC & & $15.3 \mathrm{~Gy}$ & *7.8 Gy \\
\hline Hsu et al., 2010 [81] & 10 & WBRT + SIB & LINAC & $15 \times 2,15 \mathrm{~Gy}$ & - & $5.23 \mathrm{~Gy}$ \\
\hline \multirow[t]{2}{*}{ Marsh et al., 2010 [91] } & \multirow[t]{2}{*}{11} & $\mathrm{PCl}$ & \multirow{2}{*}{$\mathrm{HT}$} & $15 \times 2 \mathrm{~Gy}$ & - & $12.5 \mathrm{~Gy}$ \\
\hline & & WBRT & & $14 X 2.5 \mathrm{~Gy}$ & - & $14.3 \mathrm{~Gy}$ \\
\hline Marsh et al., 2011 [92] & 12 & PBRT & HT & - & - & - \\
\hline van Kesteren et al., 2012 [42] & 10 & WBRT & $\begin{array}{c}\text { LINAC 3D } \\
\text { CRT }\end{array}$ & $12 \times 2.5 \mathrm{~Gy}$ & $13.5 \mathrm{~Gy}$ & $6 \mathrm{~Gy}$ \\
\hline Nevelsky et al., 2013 [93] & 10 & WBRT & IMRT & $10 \times 3 \mathrm{~Gy}$ & $14.35 \mathrm{~Gy}$ & - \\
\hline \multirow[t]{2}{*}{ Prokic et al., 2013 [83] } & \multirow[t]{2}{*}{10} & WBRT + FSRT & \multirow{2}{*}{ Rapid Arc } & $12 \times 2.5 \mathrm{~Gy}+2 \times 9 \mathrm{~Gy}$ & $12.33 \mathrm{~Gy}$ & $7.55 \mathrm{~Gy}$ \\
\hline & & $W B R T+S I B$ & & $12 \times 2.5 \mathrm{~Gy}+12 \times 4,5 \mathrm{~Gy}$ & $15.82 \mathrm{~Gy}$ & $9.8 \mathrm{~Gy}$ \\
\hline Awad et al., 2013 [94] & 30 & WBRT + SIB & Rapid Arct & $5-15 \mathrm{fr}$ & $32.2 \mathrm{~Gy}$ & $20.4 \mathrm{~Gy}$ \\
\hline Pokhrel et al., 2015 [95] & 10 & WBRT & VMAT & $30 \mathrm{~Gy} / 10 \mathrm{fr}$ & $11.2 \mathrm{~Gy}$ & $15.6 \mathrm{~Gy}$ \\
\hline \multirow[t]{2}{*}{ Kothavade et al., 2015 [96] } & \multirow[t]{2}{*}{10} & \multirow[t]{2}{*}{ PBRT } & $\mathrm{HT}$ & \multirow{2}{*}{$54 \mathrm{~Gy} / 30 \mathrm{fr}$} & - & $20 G y$ \\
\hline & & & IMRT & & - & $25 \mathrm{~Gy}$ \\
\hline Oehlke et al., 2015 [97] & 20 & WBRT + SIB & VMAT & $30 \mathrm{~Gy} / 12 \mathrm{fr}$, SIB to $51 \mathrm{~Gy}$ & - & $6.58 \mathrm{~Gy}$ \\
\hline Kim et al., 2016 [98] & 11 & WBRT + SIB & HT & $25-28 \mathrm{~Gy} / 10-14 \mathrm{fr}$, SIB to $48 \mathrm{~Gy}$ & - & $13.65 \mathrm{~Gy}$ \\
\hline Giaj Levra et al., 2016 [99] & 10 & WBRT + SIB & VMAT & $20 \mathrm{~Gy}+40 \mathrm{~Gy} / 5 \mathrm{fr}$ & $10.5 \mathrm{~Gy}$ & $7.7 \mathrm{~Gy}$ \\
\hline
\end{tabular}

dose by $56.8 \%$ in order to spare the hippocampus and yet conform to the IMRT plan as compared to when this organ is unprotected i.e. $15.8 \mathrm{~Gy}$ vs $36.6 \mathrm{~Gy}$ Gy. It should be noted that the central location of primary brain tumours often prevents shielding both hippocampi, particularly those ones immediately adjacent to the hippocampus, or those reaching into the hippocampal area because of tumour swelling [74]. Given this situation, many workers suggest sparing whichever hippocampus is tumour-free $[75,76]$.
Hippocampal sparing is especially vital to those children where primary brain tumours are diagnosed much more frequently than for adults. In children with gliomas of different histological grade, who received RT via tomotherapy, $56 \%$ and $52.1 \%$ reductions were achieved respectively in the physical or biological average doses of ionizing radiation by Marsh et al. [77] when the hippocampus is treated as a critical organ in RT planning, as compared to situations where it is not spared. 


\section{Hippocampal sparing in patients irradiated electively or those with BM}

Blomstrand et al. [78] demonstrated that a variety of RTs during WBRT given to children permitted different radiation doses to be administered to the hippocampus. They found that the average dose given to the hippocampus and SVZ was $88.3 \%$ of the planned total IMAT dose (i.e. Intensity Modulated Arc Therapy), $77.1 \%$ of the IMRT and $42.3 \%$ for IMPT (Intensity Modulated Proton Therapy). Tarnawski et al. [79] reported that it was possible to achieve a $45 \%$ dose reduction when using helical tomotherapy as well as IMRT when planning $\mathrm{PCl}$ for 10 patients suffering from small cell lung cancer, whilst still preserving the therapeutic radiation dose to the rest of brain. Similar findings were demonstrated by Gondi et al. [80] on five patients when WBRT (30Gy / 10fr) was prescribed using helical IMRT or tomotherapy, where dose levels were respectively reduced by $87 \%$ and $81 \%$ for the hippocampus. In instances of hippocampal avoidance, the therapeutic dose is still, in homogenous fashion, applied to the rest of the brain.

The lowest dose delivered to the hippocampus was achieved by Hsu et al. [81] on 10 patients with up to 3 single BMs, where SIB-VMAT (Simultaneous Integrated Boost Volumetric-Modulated Arc Therapy) was used post-WBRT, so as to increase the radiotherapy dose delivered to the BMs. The hippocampus received less than 6 Gy $(5.23 \mathrm{~Gy}$ +/- $0.23 \mathrm{~Gy}$ ) with respect to conventional fractioning after $2 \mathrm{~Gy}$, whilst maintaining the planned/proscribed dose to the rest of the brain. Likewise, Gutierrez et al. [82] demonstrated on $10 \mathrm{BM}$ patients undergoing WBRT, that it was possible to reduce the hippocampal dose to an average total of around $5.8 \mathrm{~Gy}$ with single fraction doses being 0.39 Gy, based on fractioning 2 Gy. A study by Prokic et al. [83] reported slightly higher doses, when using VMAT-SIB in BM patients also undergoing WBRT, of respectively $7.55+/-0.62$ Gy and 6.29+/- 0.62 Gy at hippocampal margins of 5 an 10 $\mathrm{mm}$ with respect to a $2 \mathrm{~Gy}$ fractionation. Additionally, it was observed that that the SIB-VMAT technique allowed doses delivered to the hippocampus to become reduced even in those patients with up to 8 multiple BMs.

The fractional dose (DF) and total dose (DC) have still not yet been unequivocally defined, which would enable limbic system function to be retained/continued. Gondi et al. [44] determined that the EQD2 (Biologically Equivalent Doses in 2 Gy Fractions), of greater than 7.3 Gy delivered to more than $40 \%$ by volume of both hippocampi results in impairment of deferred memory and problems in learning and remembering. A study by Gutierrez et al. [81] defined an acceptable DF of 0.39 Gy and DC of 5.8 Gy relative to the EQD2. Although there is no clinical data on any average dose suitable to the hippocampus, it is assumed that a DC exceeding $15.8 \mathrm{~Gy}-24.9 \mathrm{~Gy}$ is sufficient for retaining cognitive function [84].
Based on the RTOG 0933 study, preliminary recommendations were proposed for dose tolerances to the hippocampus in BM patients which could deliver a survival longer than 6 months when using WBRT, i.e. the DC should not exceed $7.8 \mathrm{~Gy}$ and the dose to the entire hippocampus should not exceed $10 \mathrm{~Gy}$, whilst the maximum dose should not rise above $15.3 \mathrm{~Gy}$ [85]. The study suggests the contouring of critical structures responsible for neurogenesis, i.e. the SVZ with a $5 \mathrm{~mm}$ margin of surrounding tissue. A contour atlas of the hippocampus can be found on the RTOG website [86].

It is finally worth mentioning about the search for objective methods for assessing cognitive impairment in patients with post-cerebral RT. In a proton MR spectroscopy study on patients that had undergone WBRT 4 months earlier, reduced concentrations of $\mathrm{N}$-acetylaspartate were noted; this being a metabolite of nerve tissue from the hippocampal region [87]. Another study using MR spectroscopy found sub-acute radiation damage to nerve tissue after a month post-WBRT [88]. It seems likely that such studies will in the future provide a more accurate assessment of cognitive impairment in patients after brain RT as opposed to those subjective methods for assessing the hippocampus, (i.e. the cognitive studies).

\section{Summary and conclusions}

RT in patients with primary and metastatic brain tumours is still an important treatment, but it remains associated with certain cognitive dysfunctions. The hippocampus is one of the brain structures that are acutely sensitive to ionizing radiation, particularly the so-called active neurogenesis regions in which NSCs proliferate. Indeed, NSC function has been proved to assure that the limbic system operates normally; this being primarily responsible for cognitive function.

Radiation damage to the hippocampus may play a key role for decreasing patient QoL after brain RT through cognitive impairment. Shortcomings in these functions commonly include problems with learning, memory, (both shortterm and deferred) and processing of information previously stored. A series of studies using subjective methods for assessing patient's cognitive functions, post-RT, by means of psychological tests such as 'mini-mental', AVLT, HVLT or COWA demonstrated a distinct loss of cognitive function already apparent at about 2-3 months after treatment. An objective test or marker capable of detecting damage to hippocampal structures is however still being sought for.

Further clinical trials are required, which would allow the best RT to be selected, thus allowing the hippocampus to be protected in a variety of specific clinical situations. It is also important to define patient groups who could tangibly benefit from hippocampal sparing when undergoing brain RT.

Conflict of interest: all authors declare no conflict of interest 


\section{Ewa Sierko, MD, PhD}

Department of Oncology, Medical University in Białystok

ul. Ogrodowa 12, 15-027 Białystok, Poland

e-mail ewa.sierko@iq.pl

\section{Received: 28 Apr 2016}

Accepted: 9 May 2016

\section{References}

1. Didkowska J, Wojciechowska U, Zatoński W. Nowotwory Złośliwe w Polsce w 2011 Roku, Centrum Onkologii - Instytut im. M. Skłodowskiej-Curie, Krajowy Rejestr Nowotworów Zakład Epidemiologii i Prewencji Nowotworów; Warszawa 2013, 13-21.

2. Parisi S, Corsa P, Raguso A et al. Temozolomide and radiotherapy versus radiotherapy alone in high grade gliomas: a very long term comparative study and literature review. Biomed Res Int 2015; 2015: 620643.

3. Rades D, Schild SE. Do patients with a limited number of brain metastases need whole-brain radiotherapy in addition to radiosurgery? Strahlenther Onkol 2012; 188: 702-706.

4. Balducci $M$, Autorino R, Chiesa $S$ et al. Radiosurgery or fractionated stereotactic radiotherapy plus whole-brain radioherapy in brain oligometastases: A long-term analysis. Anticancer Res 2015; 35: 3055-3059.

5. Aoyama $H$, Shirato $H$, Tago $M$ et al. Stereotactic radiosurgery plus whole-brain radiation therapy vs stereotactic radiosurgery alone for treatment of brain metastases: a randomized controlled trial. JAMA 2006; 295: 2483-2491.

6. Patchell RA, Tibbs PA, Regine WF et al. Postoperative radiotherapy in the treatment of single metastases to the brain: a randomized trial. JAMA 1998; 280: 1485-1489.

7. Chang EL, Wefel JS, Hess KR et al. Neurocognition in patients with brain metastases treated with radiosurgery or radiosurgery plus whole-brain irradiation: a randomised controlled trial. Lancet Oncol 2009; 10: 1037-1044.

8. Kocher $M$, Soffietti $R$, Abacioglu $U$ et al. Adjuvant whole-brain radiotherapy versus observation after radiosurgery or surgical resection of one to three cerebral metastases: results of the EORTC 22952-26001 study. J Clin Oncol 2011; 29: 134-141.

9. Li J, Bentzen SM, Renschler M et al. Regression after whole-brain radiation therapy for brain metastases correlates with survival and improved neurocognitive function. J Clin Oncol 2007; 25: 1260-1266.

10. Welzel G, Fleckenstein K, Schaefer J et al. Memory function before and after whole brain radiotherapy in patients with and without brain metastases. Int J Radiat Oncol Biol Phys 2008; 72: 1311-1318.

11. Gondi V,Tomé WA, Mehta MP.Why avoid the hippocampus? A comprehensive review. Radiother Oncol 2010, 97: 370-376.

12. Falkowski A, Kurcz I. Procesy poznawcze. W: Psychologia. Podręcznik akademicki red. Strelau J. t. 2. Gdańsk: Gdańskie Wydawnictwo Psychologiczne 2006: 23-316.

13. Meyers CA, Brown PD. Role and relevance of neurocognitive assessment in clinical trials of patients with CNS tumors. J Clin Oncol 2006; 24: 1305-1309.

14. Meyers CA, Smith JA, Bezjak A et al. Neurocognitive function and progression in patients with brain metastases treated with whole-brain radiation and motexafin gadolinium: results of a randomized phase III trial. J Clin Oncol 2004; 22: 157-165.

15. Collier TJ, Quirk GJ, Routtenberg A. Separable roles of hippocampal granule cells in forgetting and pyramidal cells in remembering spatial information. Brain Res 1987; 409: 316-328.

16. Wheeler SM, McLelland VC, Sheard E et al. Hippocampal functioning and verbal associative memory in adolescents with congenital hypothyroidism. Front Endocrinol 2015; 6: 163.

17. Kazda T, Jancalek R, Pospisil P et al. Why and how to spare the hippocampus during brain radiotherapy: the developing role of hippocampal avoidance in cranial radiotherapy. Radiat Oncol 2014; 9:139.

18. Zhao C, Deng W, Gage FH. Mechanisms and functional implications of adult neurogenesis. Cell 2008; 132: 645-660.

19. Ming GL, Song $\mathrm{H}$. Adult neurogenesis in the mammalian brain: significant answers and significant questions. Neuron 2011; 70: 687-702.

20. Wang C, Liu F, Liu YY et al. Identification and characterization of neuroblasts in the subventricular zone and rostral migratory stream of the adult human brain. Cell Res 2011; 21: 1534-1550.

21. Sanai N, Nguyen T, Ihrie RA et al. Corridors of migrating neurons in the human brain and their decline during infancy. Nature 2011; 478: 382-386.
22. van Praag $\mathrm{H}$, Schinder AF, Christie BR et al. Functional neurogenesis in the adult hippocampus. Nature 2002; 415: 1030-1034.

23. Spalding KL, Bergmann O, Alkass $\mathrm{K}$ et al. Dynamics of hippocampal neurogenesis in adult humans. Cell 2013; 153: 1219-1227.

24. Lin R, Cai J, Nathan C et al. Neurogenesis is enhanced by stroke in multiple new stem cell niches along the ventricular system at sites of high BBB permeability. Neurobiol Dis 2015; 74: 229-239.

25. Sawada M, Matsumoto M, Sawamoto K. Vascular regulation of adult neurogenesis under physiological and pathological conditions. Front Neurosci 2014; 8:53.

26. Barazzuol L, Rickett N, Ju L et al. Low levels of endogenous or X-ray-induced DNA double-strand breaks activate apoptosis in adult neural stem cells. J Cell Sci 2015; 128: 3597-3606.

27. Monje ML, Mizumatsu S, Fike JR et al. Irradiation induces neural precursor-cell dysfunction. Nat Med 2002; 8: 955-962.

28. Mizumatsu S, Monje ML, Morhardt DR et al. Extreme sensitivity of adult neurogenesis to low doses of X-irradiation. Cancer Res 2003; 63: 4021-4027.

29. Tofilon PJ, Fike JR. The radioresponse of the central nervous system: a dynamic process. Radiat Res 2000; 153: 357-370.

30. Nagai R, Tsunoda S, Hori Y et al. Selective vulnerability to radiation in the hippocampal dentate granule cells. Surg Neurol 2000; 53: 503-506.

31. Tada E, Parent JM, Lowenstein DH et al. X-irradiation causes a prolonged reduction in cell proliferation in the dentate gyrus of adult rats. Neuroscience 2000; 99: 33-41.

32. Raber J, Rola R, LeFevour A et al. Radiation-induced cognitive impairments are associated with changes in indicators of hippocampal neurogenesis. Radiat Res 2004; 162: 39-47.

33. Abayomi OK. Pathogenesis of irradiation-induced cognitive dysfunction. Acta Oncol 1996; 35: 659-663.

34. Mahajan A, Dong L, Prabhu S et al. Application of deformable image registration to hippocampal doses and neurocognitive outomces. Society of Neuro-Oncology; Dallas 2007; 538-550.

35. Jalali R, Mallick I, Dutta D et al. Factors influencing neurocognitive outcomes in young patients with benign and low-grade brain tumors treated with stereotactic conformal radiotherapy. Int J Radiat Oncol Biol Phys 2010; 77: 974-979.

36. Monje ML, Toda H, Palmer TD. Inflammatory blockade restores adult hippocampal neurogenesis. Science 2003; 302: 1760-1765.

37. Monje ML, Palmer T. Radiation injury and neurogenesis. Curr Opin Neurol 2003; 16: 129-134.

38. Monje ML, Vogel H, Masek M et al. Inhibition of hippocampal neurogenesis in humans after treatment for central nervous system malignancies. Neurol 68; 12: A289-A289.

39. Lawrence YR, Li XA, el Naqa l et al. Radiation dose-volume effects in the brain. Int J Radiat Oncol Biol Phys 2010; 76 (3 suppl): s20-27.

40. Gondi V, Tolakanahalli R, Mehta MP et al. Hippocampal-sparing whole-brain radiotherapy: a "how-to" technique using helical tomotherapy and linear accelerator-based intensity-modulated radiotherapy. Int J Radiat Oncol Biol Phys 2010; 78: 1244-1252.

41. Marsh JC, Godbole R, Diaz AZ et al. Sparing of the hippocampus, limbic circuit and neural stem cell compartment during partial brain radiotherapy for glioma: a dosimetric feasibility study. J Med Imaging Radiat Oncol 2011; 55: 442-449.

42. van Kesteren Z, Belderbos J, van Herk $M$ et al. A practical technique to avoid the hippocampus in prophylactic cranial irradiation for lung cancer. Radiother Oncol 2012; 102: 225-227.

43. Acharya MM, Lan ML, Kan VH et al. Consequences of ionizing radiation-induced damage in human neural stem cells. Free Radic Biol Med 2010; 49: 1846-1855

44. Gondi V, Hermann BP, Mehta MP et al. Hippocampal dosimetry predicts neurocognitive function impairment after fractionated stereotactic radiotherapy for benign or low-grade adult brain tumors. Int J Radiat Oncol Biol Phys 2012; 83: e487-493.

45. Gould E, McEwen BS, Tanapat $P$ et al. Neurogenesis in the dentate gyrus of the adult tree shrew is regulated by psychosocial stress and NMDA receptor activation. J Neurosci 1997; 17: 2492-2498.

46. Kempermann G, Kuhn HG, Gage FH. More hippocampal neurons in adult mice living in an enriched environment. Nature 1997; 386: 493-495.

47. Gould E, Beylin A, Tanapat P et al. Learning enhances adult neurogenesis in the hippocampal formation. Nat Neurosci 1999; 2: 260-265.

48. Kuhn HG, Dickinson-Anson H, Gage FH. Neurogenesis in the dentate gyrus of the adult rat: agerelated decrease of neuronal progenitor proliferation. J Neurosci 1996; 16: 2027-2033

49. Mizumatsu S, Monje ML, Morhardt DR et al. Extreme sensitivity of adult neurogenesis to low doses of X-irradiation. Cancer Res 2003; 63: 4021-4027. 
50. Raber J, Rola R, LeFevour A et al. Radiation-induced cognitive impairments are associated with changes in indicators of hippocampal neurogenesis. Radiat Res 2004; 162: 39-47.

51. Nagai $R$, Tsunoda $S$, Hori $Y$ et al. Selective vulnerability to radiation in the hippocampal dentate granule cells. Surg Neurol 2000; 53: 503-506.

52. Tada E, Parent JM, Lowenstein DH et al. X-irradiation causes a prolonged reduction in cell proliferation in the dentate gyrus of adult rats. Neuroscience 2000; 99: 33-41.

53. Monje ML, Toda H, Palmer TD. Inflammatory blockade restores adult hippocampal neurogenesis. Science 2003; 302: 1760-1765.

54. DeAngelis LM, Delattre JY, Posner JB. Radiation-induced dementia in patients cured of brain metastases. Neurology 1989; 39: 789-796.

55. Murray KJ, Scott C, Zachariah B et al. Importance of the mini-mental status examination in the treatment of patients with brain metastases: a report from the Radiation Therapy Oncology Group protocol 91-04. Int J Radiat Oncol Biol Phys 2000; 48: 59-64.

56. Meyers CA, Smith JA, Bezjak A et al. Neurocognitive function and progression in patients with brain metastases treated with whole-brain radiation and motexafin gadolinium: results of a randomized phase III trial. J Clin Oncol 2004; 22: 157-165.

57. Chang EL, Wefel JS, Hess KR et al. Neurocognition in patients with brain metastases treated with radiosurgery or radiosurgery plus whole-brain irradiation: a randomised controlled trial. Lancet Oncol 2009; 10: 1037-1044

58. Li J, Bentzen SM, Renschler M et al. Regression after whole-brain radiation therapy for brain metastases correlates with survival and improved neurocognitive function. J Clin Oncol 2007; 25: 1260-1266.

59. Welzel G, Fleckenstein K, Schaefer J et al. Memory function before and after whole brain radiotherapy in patients with and without brain metastases. Int J Radiat Oncol Biol Phys 2008; 72: 1311-1318.

60. Sun A, Bae K, Gore EM et al. Phase III trial of prophylactic cranial irradiation compared with observation in patients with locally advanced non-small-cell lung cancer: neurocognitive and quality-of-life analysis. $J$ Clin Oncol 2011; 29: 279-286.

61. Lee PW, Hung BK, Woo EK et al. Effects of radiation therapy on neuropsychological functioning in patients with nasopharyngeal carcinoma. J Neurol Neurosurg Psychiatry 1989; 52: 488-492.

62. Hsiao KY, Yeh SA, Chang CC et al. Cognitive function before and after intensity-modulated radiation therapy in patients with nasopharyngeal carcinoma: a prospective study. Int J Radiat Oncol Biol Phys 2010; 77: 722-726.

63. Cole AM, Scherwath A, Ernst G et al. Self-reported cognitive outcomes in patients with brain metastases before and after radiation therapy. Int J Radiat Oncol Biol Phys 2013; 87: 705-712.

64. Pinkham MB, Sanghera P, Wall GK et al. Neurocognitive Effects Following Cranial Irradiation for Brain Metastases. Clin Oncol (R Coll Radiol) 2015; 27: 630-639.

65. Scoccianti S, Ricardi U. Treatment of brain metastases: review of phase III randomised controlled trails. Radiother Oncol 2012; 102: 168-179.

66. Ogurel T, Oğurel R, Özer MA et al. Mini-mental state exam versus Montreal Cognitive Assessment in patients with diabetic retinopathy. Niger J Clin Pract 2015; 18: 786-789.

67. Brown PD, Pugh S, Laack NN et al. Memantine for the prevention of cognitive dysfunction in patients receiving whole-brain radiotherapy: a randomized, double-blind, placebo-controlled trial. Neuro Oncol 2013; 15: 1429-1437.

68. Meyers CA, Brown PD. Role and relevance of neurocognitive assessment in clinical trials of patients with CNS tumors. J Clin Oncol 2006; 24: 1305-1309.

69. Meyers CA, Smith JA, Bezjak A et al. Neurocognitive function and progression in patients with brain metastases treated with whole-brain radiation and motexafin gadolinium: results of a randomized phase III trial. J Clin Oncol 2004; 22: 157-165.

70. Regine WF, Schmitt FA, Scott CB et al. Feasibility of neurocognitive outcome evaluations in patients with brain metastases in a multi-institutional cooperative group setting: results of Radiation Therapy Oncology Group trial BR-0018. Int J Radiat Oncol Biol Phys 2004; 58: 1346-1352.

71. Gondi V, Tome WA, Marsh J et al. Estimated risk of perihippocampal disease progression after hippocampal avoidance during whole-brain radiotherapy: safety profile for RTOG 0933. Radiother Oncol 2010; 95: 327-331.

72. Marsh JC, Herskovic AM, Gielda BT et al. Intracranial metastatic disease spares the limibic circuit: a review of 697 metastatic lesions in 107 patients. Int J Radiat Oncol Biol Phys 2010; 76: 504-512.

73. Wan JF, Zhang SJ, Wang L et al. Implications for preserving neural stem cells in whole brain radiotherapy and prophylactic cranial irradiation: a review of 2270 metastases in 488 patients. J Radiat Res 2013; 54: 285-291.

74. Marsh JC, Godbole R, Diaz AZ et al. Sparing of the hippocampus, limbic circuit and neural stem cell compartment during partial brain radiotherapy for glioma: a dosimetric feasibility study. J Med Imaging Radiat Oncol. 2011; 55: 442-449.

75. Canyilmaz E, Uslu GD, Colak F et al. Comparison of dose distributions hippocampus in high grade gliomas irradiation with linac-based IMRT and VMAT: a dosimetric study. Springerplus 2015; 4: 114-121.
76. Chan JL, Lee SW, Fraass BA et al. Survival and failure patterns of high-grade gliomas after three-dimensional conformal radiotherapy. J Clin Oncol 2002; 20: 1635-1642.

77. Marsh JC, Godbole R, Diaz A et al. Feasibility of cognitive sparing approaches in children with intracranial tumors requiring partial brain radiotherapy: a dosimetric study using tomotherapy. J Cancer Ther Res 2012; 1: 1-15.

78. Blomstrand M, Brodin NP, Munck Af et al. Estimated clinical benefit of protecting neurogenesis in the developing brain during radiation therapy for pediatric medulloblastoma. Neuro Oncol 2012; 14: 882-889.

79. Tarnawski R, Michalecki L, Blamek $S$ et al. Feasibility of reducing the irradiation dose in regions of active neurogenesis for prophylactic cranial irradiation in patients with small-cell lung cancer. Neoplasma 2011; 58: 507-515

80. Gondi V, Tolakanahalli R, Mehta MP et al. Hippocampal-sparing wholebrain radiotherapy: a "how-to" technique using helical tomotherapy and linear accelerator-based intensity-modulated radiotherapy. Int $J$ Radiat Oncol Biol Phys 2010; 78: 1244-1252.

81. Hsu F, Carolan H, Nichol A et al. Whole brain radiotherapy with hippocampal avoidance and simultaneous integrated boost for 1-3 brain metastases: a feasibility study using volumetric modulated arc therapy. Int J Radiat Oncol Biol Phys 2012; 76: 1480-1485.

82. Gutiérrez AN, Westerly DC, Tomé WA et al. Whole brain radiotherapy with hippocampal avoidance and simultaneously integrated brain metastases boost: a planning study. Int J Radiat Oncol Biol Phys 2007; 69: 589-597.

83. Prokic V, Wiedenmann N, Fels F et al. Whole brain irradiation with hippocampal sparing and dose escalation on multiple brain metastases: a planning study on treatment concepts. Int J Radiat Oncol Biol Phys 2013; 85: 264-270.

84. Pinkham MB, Bertrand KC, Olson S et al. Hippocampal-sparing radiotherapy: the new standard of care for World Health Organization grade II and III gliomas? J Clin Neurosci 2014; 21: 86-90.

85. Gondi V, Pugh SL, Tome WA et al. Preservation of memory with conformal avoidance of the hippocampal neural stem-cell compartment during whole-brain radiotherapy for brain metastases (RTOG 0933): a phase II multi-institutional trial. J Clin Oncol 2014; 32: 3810-3816.

86. www.rtog.org/CoreLab/ContouringAtlases/HippocampalSparing.aspx.

87. Pospisil P, Kazda T, Bulik M et al. Hippocampal proton MR spectroscopy as a novel approach in the assessment of radiation injury and the correlation to neurocognitive function impairment: initial experiences. Radiat Oncol 2015; 10: 211-218.

88. Chawla S, Wang S, Kim S et al. Radiation injury to the normal brain measured by 3D-echo-planar spectroscopic imaging and diffusion tensor imaging: initial experience. J Neuroimaging 2015; 25: 97-104.

89. Chow $\mathrm{R}$, Tsao $\mathrm{M}$, Pulenzas $\mathrm{N}$ et al. Do patients with brain metastases selected for whole brain radiotherapy have worse baseline quality of life as compared to those for radiosurgery or neurosurgery (with or without whole brain radiotherapy)? Ann Palliat Med 2016: 5: 1-12.

90. Wolfson AH, Bae K, Komaki R et al. Primary analysis of a phase II randomized trial Radiation Therapy Oncology Group (RTOG) 0212: impact of different total doses and schedules of prophylactic cranial irradiation on chronic neurotoxicity and quality of life for patients with limited-disease small-cell lung cancer. Int J Radiat Oncol Biol Phys 2011;81:77-84.

91. Marsh JC, Gielda BT, Herskovic AM et al. Sparing of the hippocampus and limbic circuit during whole brain radiation therapy: a dosimetric study using helical tomotherapy. JMed Imaging Radiat Oncol 2010; 54:375-382.

92. Marsh JC, Godbole RH, Herskovic AM et al. Sparing of the neural stem cell compartment during whole-brain radiation therapy: a dosimetric study using helical tomotherapy. Int J Radiat Oncol Biol Phys 2010; 78: 946-954.

93. Nevelsky A, Leumwananonthachi N, Kaidar-Person O et al. Hippocampal sparing whole-brain radiotherapy using Elekta equipment. J App/ Clin Med Phys 2013; 14: 4205-4209

94. Awad R, Fogarty G, Hong A et al. Hippocampal avoidance with volumetric modulated arc therapy in melanoma brain metastases - the first Australian experience. Radiat Oncol 2013; 8: 62-67.

95. Pokhrel D, Sood S, Lominska $C$ et al. Potential for reduced radiation-induced toxicity using intensity-modulated arc therapy for whole brain radiotherapy with hippocampal sparing. J Appl Clin Med Phys 2015; 16: 5587-5593.

96. Kothavade V, Jamema SV, Gupta T et al. Which is the most optimal technique to spare hippocampus? Dosimetric comparisons of SCRT, IMRT, and tomotherapy. J Cancer Res Ther 2015; 11:358-363.

97. Oehlke $O$, Wucherpfennig $D$, Fels $F$ et al. Whole brain irradiation with hippocampal sparing and dose escalation on multiple brain metastases: Local tumour control and survival. Strahlenther Onkol 2015; 191: 461-469.

98. Kim KH, Cho BC, Lee CG et al. Hippocampus-sparing whole-brain radiotherapy and simultaneous integrated boost for multiple brain metastases from lung adenocarcinoma: early response and dosimetric evaluation. Technol Cancer Res Treat 2016; 15: 122-129.

99. Giaj Levra N, Sicignano G, Fiorentino A et al. Whole brain radiotherapy with hippocampal avoidance and simultaneous integrated boost for brain metastases: a dosimetric volumetric-modulated arc therapy study. Radiol Med 2016; 121: 60-69. 